\title{
Alloy Catalyst in a Reactive Environment: The Example of Ag-Cu Particles for Ethylene Epoxidation
}

\author{
Simone Piccinin, ${ }^{1,2}$ Spiros Zafeiratos, ${ }^{3,4}$ Catherine Stampfl, ${ }^{1}$ Thomas W. Hansen, ${ }^{3}$ Michael Hävecker, ${ }^{3}$ Detre Teschner, ${ }^{3}$ \\ Valerii I. Bukhtiyarov, ${ }^{5}$ Frank Girgsdies, ${ }^{3}$ Axel Knop-Gericke, ${ }^{3}$ Robert Schlögl, ${ }^{3}$ and Matthias Scheffler ${ }^{3}$ \\ ${ }^{1}$ School of Physics, The University of Sydney, Sydney, New South Wales 2006, Australia \\ ${ }^{2}$ CNR-INFM DEMOCRITOS National Simulation Center, Theory@Elettra Group, Trieste, Italy \\ ${ }^{3}$ Fritz-Haber-Institut der Max-Planck-Gesellschaft, Faradayweg 4-6, D-14195 Berlin, Germany \\ ${ }^{4}$ LMSPC-UMR 7515 du CNRS, Strasbourg, France \\ ${ }^{5}$ Boreskov Institute of Catalysis, SB RAS, Novosibirsk 630090, Russia
}

(Received 3 November 2009; published 22 January 2010)

\begin{abstract}
Combining first-principles calculations and in situ photoelectron spectroscopy, we show how the composition and structure of the surface of an alloy catalyst is affected by the temperature and pressure of the reagents. The $\mathrm{Ag}-\mathrm{Cu}$ alloy, recently proposed as an improved catalyst for ethylene epoxidation, forms a thin $\mathrm{Cu}-\mathrm{O}$ surface oxide, while a Ag-Cu surface alloy is found not to be stable. Several possible surface structures are identified, among which the catalyst surface is likely to dynamically evolve under reaction conditions.
\end{abstract}

DOI: 10.1103/PhysRevLett.104.035503

Industrial catalysis is often governed by transition-metal particles of nanometer-scale dimensions [1]. Temperature and partial pressures crucially determine the catalytic efficiency, and frequently the active state of the catalyst is only reached after a (macroscopic) induction period that may take milliseconds, minutes, or even days [2,3]. The existence of such an induction period reflects a noticeable modification of the catalyst material; a simple example is the development of an oxidelike film at the catalyst surface encountered in oxidation catalysis (see, e.g., [3-7]). We also like to emphasize that catalytic systems are thermodynamic open systems, which implies that the structure and composition of the active material is likely to be different from surface structures typically found in thermal equilibrium conditions.

In this Letter we report a combination of first-principles theoretical and high-pressure experimental work on the catalytic epoxidation of ethylene $\left(\mathrm{C}_{2} \mathrm{H}_{4}\right)$. There are actually two possible reaction products which have the same stoichiometry but different conformations: (i) the desired ethylene oxide $\left(\mathrm{C}_{2} \mathrm{H}_{4} \mathrm{O}\right)$ and (ii) the thermodynamically more stable, but unwanted, acetaldehyde $\left(\mathrm{CH}_{3} \mathrm{CHO}\right)$. The common catalyst for ethylene epoxidation is $\mathrm{Ag}$ on an $\alpha-\mathrm{Al}_{2} \mathrm{O}_{3}$ support. While pure $\mathrm{Ag}$ exhibits a selectivity of just $25 \%-50 \%$ towards the formation of ethylene oxide [8], recent experiments and first-principles calculations by Linic and Barteau suggest that alloying Ag with small concentrations of $\mathrm{Cu}$ noticeably improves the selectivity $[9,10]$. The rationalization of this improvement assumed the presence of a two-dimensional $\mathrm{Ag}-\mathrm{Cu}$ surface alloy [11,12]. Though these arguments may sound plausible, our density-functional theory (DFT) calculations reveal that this material is not stable in an environment containing $\mathrm{O}_{2}$ and $\mathrm{C}_{2} \mathrm{H}_{4}$ at temperatures and pressures relevant for industrial applications. In fact our results
PACS numbers: 61.82.Bg, 68.43.Bc, $81.65 . \mathrm{Mq}$

show that copper segregates to the surface forming thin oxidelike films. We find that there are several possible surface structures with similar energies, suggesting that they dynamically coexist on the Ag substrate. These predictions are confirmed by in situ X-ray photoelectron spectroscopy (XPS) measurements on Ag-Cu nanopowders in a $\mathrm{C}_{2} \mathrm{H}_{4}: \mathrm{O}_{2}(1: 2)$ atmosphere at a total pressure of $0.5 \mathrm{mbar}$ and a temperature of $520 \mathrm{~K}$, and by x-ray diffraction (XRD) and high resolution transmission electron microscopy (HRTEM) of catalysts that were removed from the reactor and analyzed under vacuum conditions.

We perform DFT calculations with the Perdew-BurkeErnzerhof generalized gradient approximation for the exchange and correlation functional [13], using a plane wave ultrasoft-pseudopotential approach as implemented in the QUANTUM-ESPRESSO package [14]. The pseudopotentials are taken from the standard QUANTUM-ESPRESSO library. To model the alloy catalyst we use a periodically repeated slab geometry [15]. The effect of the oxygen atmosphere is taken into account by employing ab initio atomistic thermodynamics $[4,17,18]$ : the structures are considered to be in thermodynamic equilibrium with an oxygen gas reservoir, described by its chemical potential. For each surface orientation, the most stable structures are the ones that minimize the surface free energy $\gamma=E_{\text {tot }}-\sum N_{i} \mu_{i}$, where $E_{\text {tot }}$ is the total energy of the system, $N_{i}$ is the number of atoms of the $i$ th element, and $\mu_{i}$ its chemical potential. Except for the oxygen reservoir, we neglect the vibrational and configurational entropy contributions [16]. The chemical potentials of $\mathrm{Ag}$ and $\mathrm{Cu}$ are fixed at their bulk values and the chemical potential of $\mathrm{O}$ is measured with respect to half the energy of the oxygen molecule $\left(\Delta \mu_{\mathrm{O}}=\mu_{\mathrm{O}}-1 / 2 E_{\mathrm{O}_{2}}^{\mathrm{tot}}\right)$. The chemical potential of oxygen can be directly linked to the temperature $(T)$ and oxygen partial pressure $\left(p_{\mathrm{O}_{2}}\right)$ [4]. In our previous publications 
$[16,19]$ we showed how the strength of the $\mathrm{Cu}-\mathrm{O}$ interaction relative to the $\mathrm{Ag}-\mathrm{O}$ one drives $\mathrm{Cu}$ to the surface, where it tends to form thin oxidelike layers. However, it is important also to consider the effect of the reducing agent (ethylene) present in the atmosphere on the range of stability of these surface structures. To this end we perform an analysis analogous to the one presented for the $\mathrm{Ru}-\mathrm{O}$ system in Ref. [5]. By this "constrained thermodynamic equilibrium" approach we consider the stability of the thin oxidelike layers toward the oxidation of ethylene to acetaldehyde (the thermodynamically favored reaction product). Indicating with $\mathrm{Ag}_{x} \mathrm{Cu}_{y} \mathrm{O}_{z}$ the stoichiometry of surface structures, and approximating the chemical potential of acetaldehyde with its internal energy in the gas phase, the condition of stability is $\Delta \mu_{\mathrm{C}_{2} \mathrm{H}_{4}}-\Delta \mu_{\mathrm{O}} \lesssim$ $-\frac{2}{z} H_{f}(T=0 \mathrm{~K})+\Delta E^{\mathrm{mol}}$. Here $\Delta \mu_{\mathrm{C}_{2} \mathrm{H}_{4}}$ is the ethylene chemical potential, measured with respect to its zero temperature value, $H_{f}(T=0 \mathrm{~K})$ is the zero temperature formation energy of the surface structure, and $\Delta E^{\mathrm{mol}}=E_{\mathrm{CH}_{3} \mathrm{CHO}}-E_{\mathrm{C}_{2} \mathrm{H}_{4}}-1 / 2 E_{\mathrm{O}_{2}}$, which we calculated to be $-2.18 \mathrm{eV}$. For low values of $\Delta \mu_{\mathrm{C}_{2} \mathrm{H}_{4}}$, where the presence of ethylene can be neglected, the condition of stability is simply $\Delta \mu_{\mathrm{O}} \gtrsim \frac{1}{z} H_{f}(T=0 \mathrm{~K})$.

Since the average $\mathrm{Cu}$ coverage measured experimentally is found be less than 1 ML [10], we focus our discussion and Fig. 1 to the (111) facet and fix the $\mathrm{Cu}$ coverage at 0.5 ML. In Fig. 1 we display the surface phase diagram of this system. This shows that in the range of temperatures and pressures typically encountered under experimental conditions (see the black dashed line) several structures can be present at the surface, all of which are stable against reduction by ethylene leading to the formation of $\mathrm{CH}_{3} \mathrm{CHO}$ (solid lines) or $\mathrm{C}_{2} \mathrm{H}_{4} \mathrm{O}$ (dot-dashed lines). We verified that these conclusions hold also for the other low-index surfaces around the same coverage: on the (110) and (100) facets all the thin oxides are stable, while on the (111) the lowest $\mathrm{Cu}$ coverage leading to stable thin oxides is around $0.2 \mathrm{ML}$. These findings allow us to neglect the effect of the presence of ethylene in the following and to focus on the effects of the oxygen atmosphere while varying the $\mathrm{Cu}$ surface content. To this end we now fix the value of oxygen chemical potential at a value corresponding to $T=600 \mathrm{~K}$ and $p_{\mathrm{O}_{2}}=1 \mathrm{~atm}\left(\Delta \mu_{\mathrm{O}}=-0.61 \mathrm{eV}\right)$ and use the chemical potential of $\mathrm{Cu}$ as a parameter that controls the $\mathrm{Cu}$ content in the catalyst. We restrict ourselves to the three low-index surfaces (111), (100), and (110), neglecting edge effects.

In Fig. 2 we display the surface free energies of the most stable structure on each of the three facets as a function of the chemical potential of $\mathrm{Cu}$. For a few selected values of $\Delta \mu_{\mathrm{Cu}}$ we also show the predicted shape of the particle, obtained by minimizing its free surface energy according to the Wulff construction procedure. At the chosen value of temperature and oxygen partial pressure, the value of $\Delta \mu_{\mathrm{Cu}}$ above which $\mathrm{Cu}$ oxidizes to bulk copper oxide is $-0.62 \mathrm{eV}$. We find that the values of $\Delta \mu_{\mathrm{Cu}}$ compatible

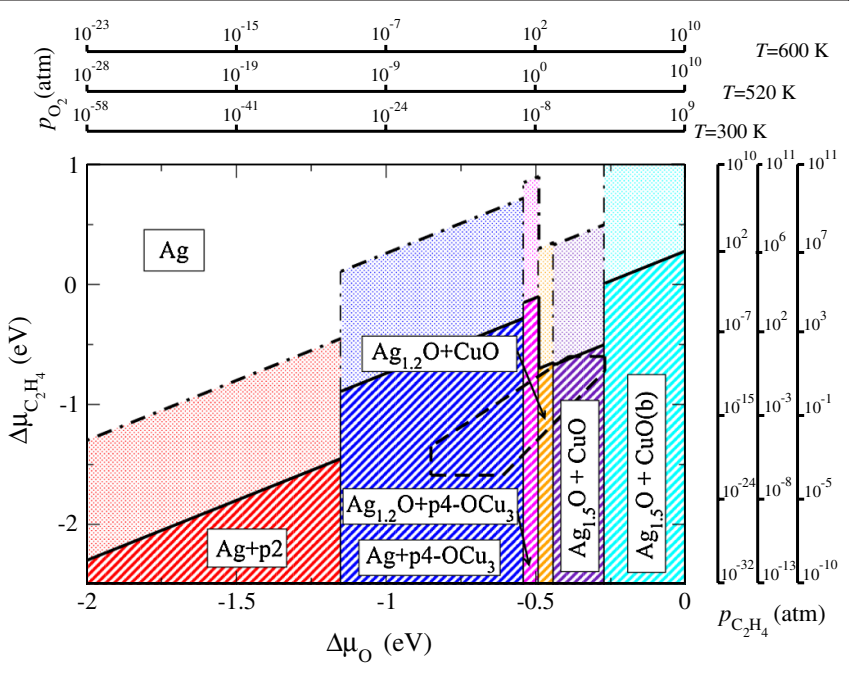

FIG. 1 (color online). Surface phase diagram for the (111) facet under constrained thermodynamic equilibrium with oxygen and ethylene. Solid (dot-dashed) lines represent the stability limit with respect to the formation of $\mathrm{CH}_{3} \mathrm{CHO}\left(\mathrm{C}_{2} \mathrm{H}_{4} \mathrm{O}\right)$. Each shaded area represents the region of stability of a combination of two surface structures giving a Cu coverage of $0.5 \mathrm{ML}$. The white area is the region of stability of the clean $\operatorname{Ag}(111)$ surface. The dashed polygon corresponds to typical values of temperature and pressures used in experiments $(T=300-600 \mathrm{~K}$ and $p_{\mathrm{O}_{2}}, p_{\mathrm{C}_{2} \mathrm{H}_{4}}=10^{-4}-1$ atm). $\operatorname{Ag}_{1.2} \mathrm{O}$ and $\mathrm{Ag}_{1.5} \mathrm{O}$ are 1-layer thin oxidelike structures; $\mathrm{CuO}$ and $\mathrm{CuO}(\mathrm{b})$ are 1-layer thin and bulk $\mathrm{CuO}$ structures, respectively; $p 2$ and $p 4-\mathrm{OCu}_{3}$ are 1-layer thin $\mathrm{Cu}_{2} \mathrm{O}$-like structures with $(2 \times 2)$ and $(4 \times 4)$ periodicity, respectively. In the latter, a $\mathrm{OCu}_{3}$ unit is removed.

with the experimental $\mathrm{Cu}$ coverages (0.1-0.75 ML [10]) are those just around the formation of bulk copper oxide. From Fig. 2 it is evident that, contrary to pure Ag, the (111) facet is not the dominant one.

Around the region of interest, both the (100) and (110) surfaces are covered with a one layer thin oxidelike structure with a 1:1 stoichiometry between $\mathrm{Cu}$ and $\mathrm{O}$. We denote these thin-layer structures with the label "CuO", even though they bear little to no resemblance to bulk $\mathrm{CuO}$ oxide (see Fig. 2). For values of $\Delta \mu_{\mathrm{Cu}}$ below $-0.65 \mathrm{eV}$ all facets are covered with $\mathrm{Cu}$-free structures, while the twodimensional $\mathrm{Ag}-\mathrm{Cu}$ surface alloy is not present, in these conditions, on any of the low-index facets.

A confirmation of these theoretical predictions comes from our in situ photoelectron spectroscopy experiments, performed at beam line U49/2-PGM1 at BESSY II in Berlin, in a setup described elsewhere [20]. Commercial copper-silver nanopowder ( $100 \mathrm{~nm}, 2.5 \mathrm{wt} \% \mathrm{Cu}$, SigmaAldrich $\left.{ }^{\circledR}\right)$, was used. For the quantitative calculations the spectra were normalized to the storage ring current, the incident photon flux and the atomic subshell photoionization cross section [21]. The sample was measured at $520 \mathrm{~K}$ in $\mathrm{O}_{2}, \mathrm{H}_{2}$, and a $\mathrm{C}_{2} \mathrm{H}_{4}: \mathrm{O}_{2}(1: 2)$ atmospheres at a total pressure of 0.5 mbar. Quadrupole and a proton transfer reaction mass spectrometry were used to monitor the gas phase simultaneously to the spectroscopic characteriza- 


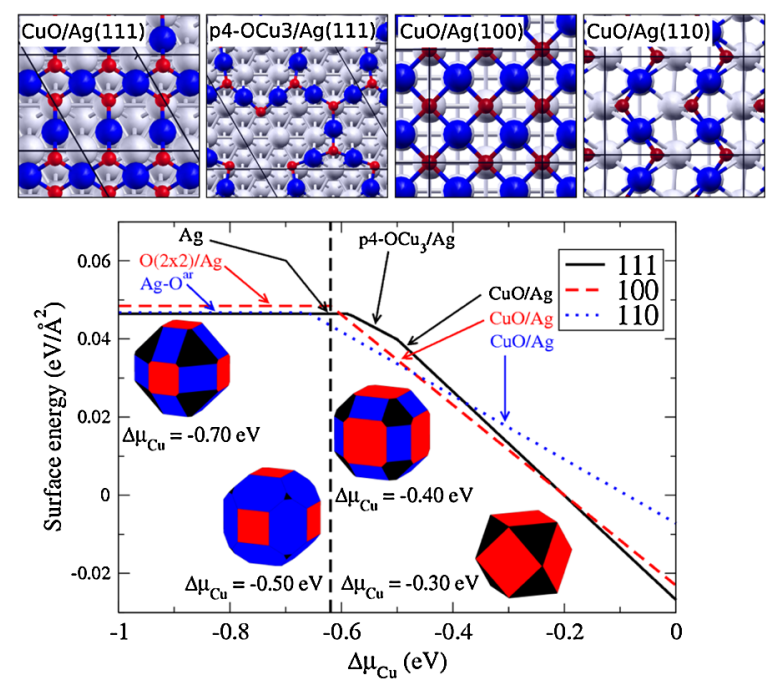

FIG. 2 (color online). Top: relaxed geometries of four of the most stable oxidelike structures. Large (gray) spheres represent $\mathrm{Ag}$ atoms, small (red) spheres $\mathrm{O}$ atoms and dark (blue) spheres $\mathrm{Cu}$ atoms. Bottom: Surface energy of the most stable surface structures on each of the three surface orientations as a function of the $\mathrm{Cu}$ chemical potential. At selected $\mathrm{Cu}$ chemical potentials, also a model of a catalyst particle obtained through the Wulff construction is presented. $\Delta \mu_{\mathrm{O}}$ is set to $-0.61 \mathrm{eV}$ (corresponding to $T=600 \mathrm{~K}$ and $\left.p_{\mathrm{O}_{2}}=1 \mathrm{~atm}\right)$.

tion. Although gas phase analysis data are not presented in this Letter, it should be noted that significant increase of $\mathrm{C}_{2} \mathrm{H}_{4} \mathrm{O}$ and $\mathrm{CO}_{2}$ gas phase signals was detected under the reaction conditions studied here, indicating that spectroscopic characterization was performed on the catalytically active $\mathrm{Ag}-\mathrm{Cu}$ surface.

In Fig. 3 core level [Fig. 3(a)] and valence band [Fig. 3(b)] photoemission spectra recorded in oxygen and ethylene or oxygen atmospheres are presented. In addition, reference valence band spectra of metallic $\mathrm{Cu}, \mathrm{Cu}_{2} \mathrm{O}$, and $\mathrm{CuO}$ are also included for comparison. In Fig. 3(a) the photoelectron $\mathrm{Cu} 2 p_{3 / 2}$ peak at about $933 \mathrm{eV}$ is accompanied by a satellite structure on the high binding energy side. The peak fit of the spectrum indicates two copper components (with FWHM in parentheses) at 932.3 (1.5) and 934.0 (2.0) $\pm 0.1 \mathrm{eV}$ and a set of shakeup satellite features at 941.0 and $943.5 \mathrm{eV}$. The shakeup satellites are characteristic of materials having $d^{9}$ configuration in the ground state, i.e., $\mathrm{Cu}^{2+}[22,23]$. Therefore one can assign the peak at $934.0 \mathrm{eV}$ together with the satellite structures to $\mathrm{Cu}^{2+}$ states, e.g., CuO-like structures. The peak at $932.3 \mathrm{eV}$ originates either from metallic $\mathrm{Cu}$ or $\mathrm{Cu}^{+}$states (e.g., $\mathrm{Cu}_{2} \mathrm{O}$ ), since their core level spectra have the same binding energy [22,23]. Although $\mathrm{Cu} 2 p$ core level peak is not suitable to distinguish between metallic $\mathrm{Cu}$ and $\mathrm{Cu}_{2} \mathrm{O}$, these two copper states show pronounced differences in the valence band spectrum. The valence band of the $\mathrm{Ag}-\mathrm{Cu}$ catalyst [Fig. 3(b), left panel] is dominated by the $\mathrm{O} 2 p$ states between the Fermi edge and $2 \mathrm{eV}, \mathrm{Cu} 3 d$ states around $3 \mathrm{eV}$ and $\mathrm{Ag} 4 d$ states between 4 and $8 \mathrm{eV}$

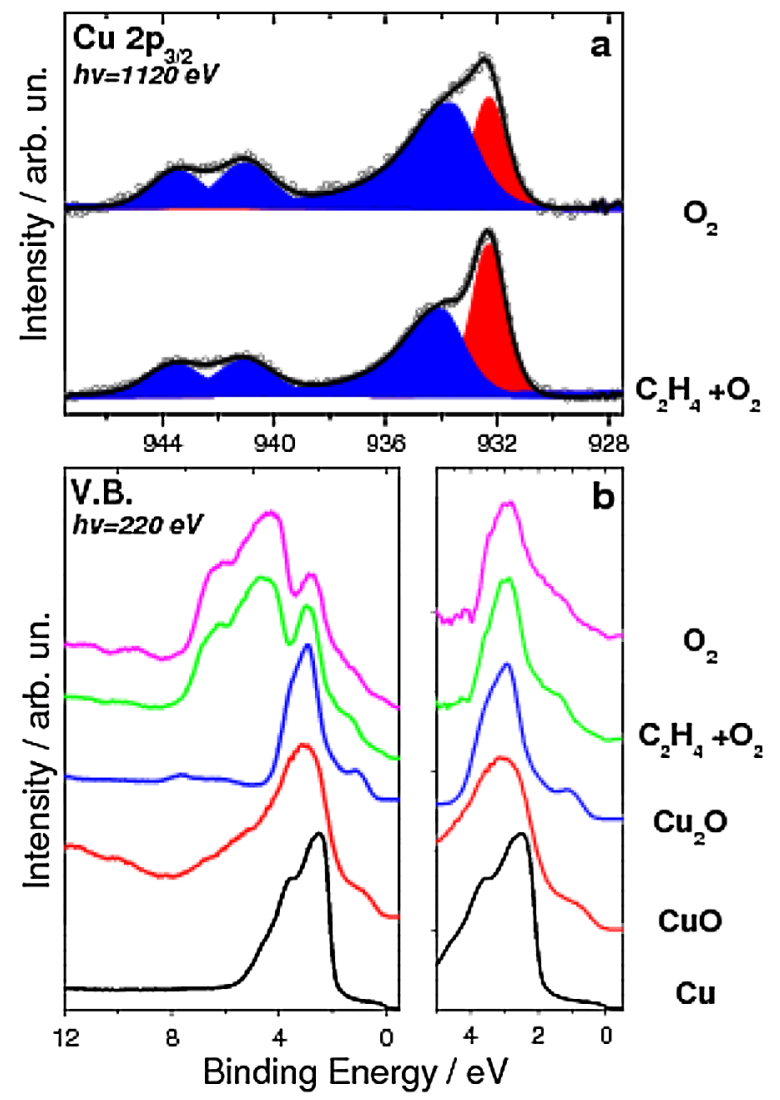

FIG. 3 (color online). (a) The $\mathrm{Cu} 2 p_{3 / 2}$ core level spectra of the $\mathrm{Ag}-\mathrm{Cu}$ catalyst recorded under oxygen and reaction $\left(\mathrm{C}_{2} \mathrm{H}_{4}: \mathrm{O}_{2}\right)$ atmospheres (total pressure 0.5 mbar at $520 \mathrm{~K}$ ). (b) Valence band spectra of the Ag-Cu catalyst under oxygen and reaction atmospheres (left). The valence band region close to the Fermi edge obtained from the difference spectra between Ag$\mathrm{Cu}$ and pure $\mathrm{Ag}$ samples (right). At the bottom, valence band spectra of reference oxides are given.

$[24,25]$. As can be clearly seen in the reference spectra, metallic and oxidized copper exhibit different characteristic features in the valence band in full agreement with previous measurements on copper oxides using UV radiation $[22,24]$. In particular, the center of the $\mathrm{Cu} 3 d$ band is shifted from $2.5 \mathrm{eV}$ on metallic, to $3 \mathrm{eV}$ on $\mathrm{Cu}$ oxides, with the later showing an additional intense feature $1 \mathrm{eV}$ below the Fermi edge. In the valence band of the Ag-Cu catalyst the center of $\mathrm{Cu} 3 d$ band is located at $3 \mathrm{eV}$, while an intense feature at around $1.4 \mathrm{eV}$ is also observed. This can more clearly be seen in the right panel of Fig. 3(b), where the difference spectra between the $\mathrm{Ag}-\mathrm{Cu}$ catalyst and pure $\mathrm{Ag}$ are shown. The resemblance of the $\mathrm{Cu} 3 d$ features in $\mathrm{Ag}-\mathrm{Cu}$ samples with those of reference $\mathrm{Cu}_{2} \mathrm{O}$ and $\mathrm{CuO}$ indicates that copper oxide and not metallic or alloyed copper is dominating the surface. Consequently, one can assign the core level $\mathrm{Cu} 2 p_{3 / 2}$ component at $932.3 \mathrm{eV}$ predominantly due to $\mathrm{Cu}_{2} \mathrm{O}$-like oxide species.

In Table I the calculated $\mathrm{Ag}, \mathrm{Cu}, \mathrm{O}, \mathrm{C}$, and $\mathrm{Cu} / \mathrm{Ag}$ atomic ratios $\left(X_{i}=100 \times N_{i} / N_{\text {tot }}\right.$, where $N_{i}$ is the number of surface atoms of kind $i$ and $N_{\text {tot }}$ the total number of 
TABLE I. The Ag, $\mathrm{Cu}, \mathrm{O}, \mathrm{C}$ atomic ratios (indicated by $X_{i}$, see text) and $\mathrm{Cu} / \mathrm{Ag}$ surface stoichiometry (indicated by $y$ ) calculated by photoemission spectroscopy. The results were recorded at $300 \mathrm{~K}$ in vacuum and at $520 \mathrm{~K}$ in $0.5 \mathrm{mbar} \mathrm{O}_{2}, \mathrm{C}_{2} \mathrm{H}_{4} / \mathrm{O}_{2}(1: 2)$ and $\mathrm{H}_{2}$ gas phase atmospheres.

\begin{tabular}{lcrrrc}
\hline \hline Conditions & $X_{\mathrm{Ag}}$ & $X_{\mathrm{Cu}}$ & $X_{\mathrm{O}}$ & \multicolumn{1}{c}{$X_{\mathrm{C}}$} & $y\left(\mathrm{Cu}_{y} \mathrm{Ag}\right)$ \\
\hline Vacuum & 16.9 & 3.2 & 28.9 & 51.0 & 0.2 \\
$\mathrm{O}_{2}$ & 32.1 & 35.9 & 31.4 & 0.6 & 1.1 \\
$\mathrm{C}_{2} \mathrm{H}_{4} / \mathrm{O}_{2}$ & 25.1 & 35.0 & 39.9 & $<0.2$ & 1.4 \\
$\mathrm{H}_{2}$ & 24.7 & 12.7 & 19.2 & 43.4 & 0.5 \\
\hline \hline
\end{tabular}

surface atoms) recorded in vacuum and various gas atmospheres are shown, assuming a homogeneous distribution of these elements on the surface. On the fresh sample there is about 8 times more copper on the surface compared to the nominal bulk composition of the sample $(2.5 \% \mathrm{Cu})$. However, surface segregation of $\mathrm{Cu}$ is greatly enhanced in oxygen and reaction atmosphere, with almost 50 times more surface copper compared to the nominal bulk composition, in line with our theoretical results. The surface remains enriched in copper even in a hydrogen atmosphere, yet to a significantly lower extent. It is also evident that a significant amount of oxygen is present on the surface, in agreement with the observation of surface copper oxide formation. However, the calculation of $\mathrm{Cu} / \mathrm{O}$ stoichiometry by $\mathrm{Cu}$ and $\mathrm{O}$ intensities is not straightforward, since it is not clear if part of this oxygen is adsorbed also on silver. Besides, under ethylene epoxidation reaction conditions, additional oxygen species are taking part in the reaction and contribute to the overall O $1 s$ spectrum [26].

XRD measurements indicate only Ag related diffraction patterns. The lattice parameter of the $\mathrm{Ag}-\mathrm{Cu}$ nanopowder did not change after the ethylene epoxidation reaction, implying that the bulk of the $\mathrm{Ag}-\mathrm{Cu}$ particles is stable under reaction conditions. An analysis of the FWHM of the diffraction peaks did not give a hint on particle sintering to a higher extent. A comparison of the lattice parameter with $\mathrm{Ag}$ nanopowder of similar grain size shows a significant expansion of the lattice in the $\mathrm{Ag}-\mathrm{Cu}$ nanopowder. This is an indication for the solution of $\mathrm{Cu}$ in the Ag lattice. Since no $\mathrm{Cu}$ related diffraction pattern is observed it can be concluded that the XPS signal of the copper oxide is related to a very thin surface layer of the particles and not to the bulk. HRTEM images (see supplementary material [27]) show the segregation of $\mathrm{Cu}$ oxide patches on the surface of the Ag particles as well as pure Ag surfaces.

In conclusion, our theoretical and experimental results consistently show that under reaction conditions the catalyst surface is very different from the hitherto assumed Ag$\mathrm{Cu}$ surface alloy. Although our theoretical study is limited to the thermodynamics of the catalyst in the reactive environment, it suggests a dynamical coexistence of thin $\mathrm{CuO}$ and $\mathrm{AgO}-\mathrm{CuO}$ films on the $\mathrm{Ag}$ substrate. This is supported by the experimental evidence that $\mathrm{Cu}$ is in an oxidized state and by the theoretical prediction of energetically similar oxidic surface structures. This is likely to have important consequences for the understanding of the mechanism by which $\mathrm{Cu}$ enhances the catalyst selectivity, since the active $\mathrm{O}$ species, rather than $\mathrm{O}$ atoms chemisorbed on a metal surface, are $\mathrm{O}$ atoms which are part of an oxide layer.

[1] B. Hodnett, Heterogeneous Catalytic Oxidation (John Wiley and Sons, Ltd., Chichester, U.K., 2000).

[2] Handbook on Heterogeneous Catalysis, edited by J. W. G. Ertl and H. Knoezinger (Wiley, New York, 1997).

[3] C. Stampfl et al., Surf. Sci. 500, 368 (2002).

[4] K. Reuter and M. Scheffler, Phys. Rev. B 65, 035406 (2001).

[5] K. Reuter et al., Appl. Phys. A 78, 793 (2004).

[6] J. Nørskov et al., MRS Bull. 31, 669 (2006).

[7] F. Tao et al., Science 322, 932 (2008).

[8] K. Weissermel and H.J. Arpe, Industrial Organic Chemistry (VCH, Weinheim, 1993).

[9] S. Linic et al., J. Catal. 224, 489 (2004).

[10] J. T. Jankowiak et al., J. Catal. 236, 366 (2005).

[11] S. Linic et al., J. Am. Chem. Soc. 125, 4034 (2003).

[12] A. Kokalj et al., J. Catal. 254, 304 (2008).

[13] J. P. Perdew, K. Burke, and M. Ernzerhof, Phys. Rev. Lett. 77, 3865 (1996).

[14] P. Giannozzi et al., J. Phys. Condens. Matter 21, 395502 (2009).

[15] All the slabs are 4 layers thick, separated by $12 \AA$ of vacuum. For all structures the $\mathbf{k}$-point sampling is equivalent (or close) to a regular $(12 \times 12)$ uniform grid on the $(1 \times 1)$ surface unit cell of the (111) surface, and we use a smearing parameter of $0.03 \mathrm{Ry}$. Most of the structures investigated have a $(2 \times 2)$ unit cell. The kinetic energy cutoff for the plane wave expansion is $27 \mathrm{Ry}$. See Ref. [16] for further details.

[16] S. Piccinin, C. Stampfl, and M. Scheffler, Phys. Rev. B 77, 075426 (2008).

[17] C. Weinert and M. Scheffler, Mater. Sci. Forum 10-12, 25 (1986).

[18] M. Scheffler and J. Dabrowski, Philos. Mag. A 58, 107 (1988).

[19] S. Piccinin et al., Surf. Sci. 603, 1467 (2009).

[20] M. Salmeron and R. Schlögl, Surf. Sci. Rep. 63, 169 (2008).

[21] J. Yeh and I. Lindau, At. Data Nucl. Data Tables 32, 1 (1985).

[22] J. Ghijsen et al., Phys. Rev. B 38, 11322 (1988).

[23] C. Chusuei et al., Langmuir 15, 2806 (1999).

[24] T. Schedel-Niedrig, M. Hävecker, A. Knop-Gericke, and R. Schlögl, Phys. Chem. Chem. Phys. 2, 3473 (2000).

[25] V. M. Trontl et al., Surf. Sci. 551, 125 (2004).

[26] V. Bukhtiyarov et al., J. Catal. 238, 260 (2006).

[27] See supplementary material at http://link.aps.org/ supplemental/10.1103/PhysRevLett.104.035503 for HRTEM images. 